\title{
Morfologi, Anatomi dan Indeks Ekologi Bulu Babi di Pantai Sepanjang, Kabupaten Gunungkidul, Yogyakarta
}

\author{
Suryanti Suryanti*, Prasasti Nusa Pertiwi Nur Fatimah, Siti Rudiyanti \\ Departemen Sumberdaya Akuatik, Fakultas Perikanan dan Ilmu Kelautan, Universitas Diponegoro \\ Jl. Prof. Sudarto, SH, Tembalang, Semarang, Jawa Tengah, 50275 \\ Email : suryantidr@gmail.com
}

\begin{abstract}
Abstrak
Pantai Sepanjang memiliki karakteristik pantai dengan substrat berupa pasir dan hamparan karang mati yang banyak ditumbuhi makroalga, merupakan habitat berbagai jenis biota, salah satunya bulu babi. Biota tersebut memiliki fungsi ekologi sebagai pemakan detritus dan pengendali populasi makroalga di ekosistem terumbu karang. Tujuan penelitian ini untuk mengetahui jenis, morfologi, anatomi, dan kelimpahan bulu babi serta hubungannya dengan parameter lingkungan. Penelitian dilaksanakan pada bulan November 2019 di Pantai Sepanjang, Kabupaten Gunungkidul. Metode sampling menggunakan stratified random sampling dengan membagi lokasi pengamatan menjadi 3 stasiun (A, B, C) berdasarkan perbedaan tutupan substrat dasar perairan. Pengamatan dilakukan terhadap jenis, morfologi, anatomi, kelimpahan dan parameter lingkungan. Hasil penelitian ditemukan 6 jenis Bulu Babi yaitu Echinometra mathaei, Echinometra oblonga, Echinothrix calamaris, Heterocentrotus trigonarius, Diadema setosum dan Stomopneustes variolaris. Enam Jenis Bulu Babi tersebut memiliki karakteristik morfologi dan anatomi yang berbeda. Kelimpahan bulu babi pada stasiun A sebesar 474 ind/ $15 \mathrm{~m}^{2}$, stasiun B sebesar $611 \mathrm{ind} / 15 \mathrm{~m}^{2}$ dan stasiun $\mathrm{C}$ sebesar $81 \mathrm{ind} / 15 \mathrm{~m}^{2}$. Berdasarkan Uji korelasi menunjukkan bahan organik sedimen berkorelasi positif, sedangkan tekstur sedimen, suhu, salinitas berkorelasi negatif dengan kelimpahan bulu babi.
\end{abstract}

Kata Kunci : Bulu babi, Morfologi, Anatomi, Parameter lingkungan, Pantai Sepanjang

\section{Abstract \\ Morphology, Anatomy and Ecological Index of Sea urchins on the coast along, Gunungkidul Regency, Yogyakarta}

Sepanjang Beach has the characteristics of sand substrates and covered by dead corals, which are overgrown by macroalgae, and is a habitat for various types of biota, one of them sea urchins. This biota has an ecological function as a detritus feeder and macroalgae population controller in a coral reef ecosystem. The aims of the study is to determine the type, morphology, anatomy, and the linkage between the abundance of sea urchins to environmental parameters. The study was conducted in November 2019 at Sepanjang Beach, Gunungkidul Regency. The stratified random sampling was applied as sampling method, by dividing the observation location into 3 stations $(A, B, C)$ based on the difference coverage of substrate. The observation covers the type, morphology, anatomy, abundance, and the environmental parameter. There were 6 sea urchins species namely Echinometra mathaei, Echinometra oblonga, Echinothrix calamaris, Heterocentrotus trigonarius, Diadema setosum and Stomopneustes variolaris, which have different characteristics of morphology and anatomy. The abundance of sea urchins at station $A$ is 474 ind $/ 15 \mathrm{~m}^{2}$, station $B$ is 611 ind/ $15 \mathrm{~m}^{2}$, and station $C$ is $81 \mathrm{ind} / 15 \mathrm{~m}^{2}$. The sediment organic material and the abundance of sea urchins showed a significant correlation, while sediment texture, temperature, salinity have an insignificant correlation to the abundance of sea urchins.

Keywords : Sea urchins, Morphology, Anatomy, Environment parameter, Sepanjang Beach 


\section{PENDAHULUAN}

Bulu babi (Sea urchins) termasuk kedalam filum Echinodermata kelas Echinoidea, tersebar mulai dari perairan dangkal hingga ke laut dalam, keanekaragaman tinggi hewan ini banyak ditemukan di zona intertidal. Persebaran bulu babi pada suatu wilayah terkait dengan substrat dasar perairan dan makanan. Oleh karenanya biota tersebut dapat dijumpai di berbagai macam habitat seperti rataan terumbu, daerah pertumbuhan alga, padang lamun, koloni karang hidup maupun karang mati. Bulu babi merupakan salah satu spesies yang berperan penting bagi komunitas terumbu karang, sebagai pengendali populasi makroalga yang menempati area tertentu bersamasama dengan terumbu karang (Suryanti et al., 2017)

Bulu babi secara ekologi memiliki fungsi sebagai pemakan detritus, pemakan partikelpartikel kecil dan penyeimbang di ekosistem terumbu karang. Bulu babi dianggap sebagai hewan herbivor, namun pada lingkungan yang berbeda dapat beradaptasi terhadap lingkungannya dengan memakan krustacea, karang dan berbagai jenis makroalga (Ristanto et al., 2017). Keberadaan bulu babi di suatu ekosistem terkait dengan karakteristik substrat, habitat yang spesifik, namun beberapa jenis mampu hidup pada daerah yang berbeda seperti pada bebatuan, celah karang maupun pecahan karang (Suryanti et al., 2017).

Pantai Sepanjang, Gunungkidul, Yogyakarta, merupakan pantai yang memiliki karakteristik berupa pasir kasar dan hamparan karang mati yang banyak ditumbuhi oleh makroalga. Pantai tersebut merupakan habitat dari berbagai jenis biota laut, dimana salah satu yang banyak ditemukan yaitu Echinodermata, dari jenis Ophiuroidea, Echinoidea dan Holothuroidea.

Menurut Prasetyo et al. (2019) bahwa kelompok Echinodermata merupakan kelompok biota laut yang cukup menonjol di Pantai Gunungkidul adalah dari kelas Echinoidea atau bulu babi. Namun demikian penelitian mengenai kehadiran bulu babi, morfologi, anatomi serta indeks ekologi bulu babi di Gunungkidul khususnya Pantai Sepanjang belum pernah dilakukan= Tujuan dari penelitian ini untuk mengetahui Jenis, Morfologi, Anatomi, kondisi lingkungan dan korelasinya terhadap kelimpahan bulu babi di ekosistem tersebut.

\section{MATERI DAN METODE}

Pengambilan sampel bulu babi dilakukan dengan menggunakan metode stratified random sampling (Raupong, 2015), yang dilakukan pada 3 stasiun, dimana setiap stasiun dibagi menjadi 3 titik, sehingga terdapat 9 titik pengamatan. Penentuan stasiun berdasarkan perbedaan tutupan substrat dasar perairan, yaitu stasiun A berupa pasir, lamun, karang mati dan makroalga,; stasiun B karang mati dan didominasi makroalga jenis Ulva sp.; stasiun C berupa karang mati dan didominasi makroalga jenis Sargassum sp. (Gambar 1).

Penentuan titik pengambilan sampel yaitu saat surut terendah dengan menarik line transek tegak lurus arah pantai hingga ditemukan pertama

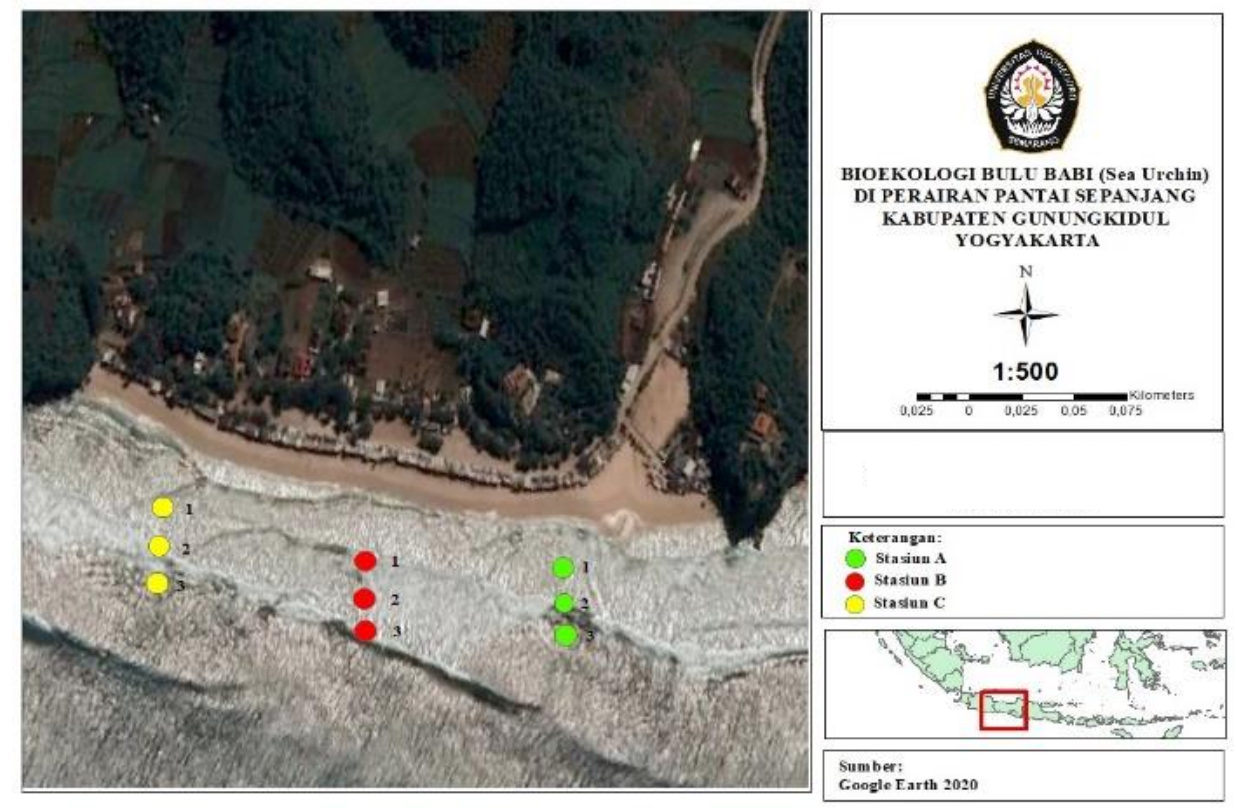

Gambar 1. Peta Lokasi Pengamatan 
kali bulu babi, kemudian meletakan kuadran transek $1 \times 1$ meter sejajar garis pantai sebanyak 5 kali, jarak antar titik yaitu 5 meter. Sampling dilaksanakan pada Bulan November 2019, dengan pertimbangan stasiun pengambilan sampel memiliki tipe tutupan substrat dasar perairan yang berbeda, stasiun pengambilan sampel merupakan tempat yang sering ditemukan bulu babi dan penentuan titik pengambilan sampel berdasarkan pertama kali bulu babi ditemukan.

Sampel bulu babi yang didapat di setiap titik pengamatan kemudian dihitung dan diambil satu sampel bulu babi yang mewakili dari setiap jenis, Pengukuran parameter lingkungan meliputi salinitas, suhu, $\mathrm{pH}$, kecerahan dan kedalaman. Pengamatan sedimen meliputi Tekstur sedimen menggunakan metode Eleftheriou dan Mc Intyre (2005), sedangkan pengamatan bahan organik sedimen menggunakan metode LOI (loss on Ignition) ( Heiri et al., 2001).

Identifikasi dilakukan dengan mengamati ciri- ciri bulu babi, kemudian mencocokkan atau membandingkan warna, bentuk tubuh dan berat sesuai kriteria Worms (2020). Pengamatan morfologi bulu babi meliputi bentuk tubuh, warna dan morfometriknya seperti berat tubuh serta panjang duri. Identifikasi morfologi bulu babi yang ditemukan menggunakan panduan identifikasi menurut Radjab (2001).

Hasil identifikasi jumlah dan jenis bulu babi kemudian dianalisis dengan menghitung kelimpahan relatif (KR), Indeks keanekaragaman $\left(H^{\prime}\right)$, Indeks Keseragaman (e) dan Indeks Dominansi (C), berdasarkan rumus dari (Odum, 1993). Dari hasil identifikasi selanjutnya diamati karakteristik morfologi dan menganalisis keeratan parameter lingkungan dengan kelimpahan bulu babi dilakukan dengan analisis korelasi. (Nasution, 2019).

\section{HASIL DAN PEMBAHASAN}

Bulu babi termasuk ke dalam filum Echinodermata kelas Echinoidea. Berdasarkan hasil Penelitian didapatkan 6 jenis bulu babi terdiri dari 3 Famili yaitu Echinometridae sebanyak 3 jenis, Diadematidae sebanyak 2 jenis dan Stomopneustidae sebanyak 1 jenis. Karakteristik morfologi jenis bulu babi yang ditemukan di lokasi penelitian terdapat perbedaan baik dari bentuk tubuh, warna maupun organ luar, selengkapnya dapat dilihat pada Tabel 1 .

Morfologi merupakan bentuk luar suatu organisme merupakan salah satu ciri yang mudah dilihat dan mudah diingat dalam mempelajari organisme. Adapun yang dimaksud dengan bentuk luar organisme adalah bentuk tubuh dan warna tubuh yang terlihat dari luar.

Echinometra mathaei (Gambar 2.) memiliki berat berkisar antara 20,29-67,54 gram dengan diameter 38-51 mm, panjang duri primer 8-13 $\mathrm{mm}$, duri sekunder 2-5 mm. memiliki duri tegak, permukaan halus dan ujung runcing berwarna coklat muda, cangkang berbentuk oval, berwarna coklat gelap. Ciri khas spesies ini yaitu terdapat cincin berwarna putih pada pangkal durinya, bentuk Tuberkel perforate. Pola sebaran E. mathaei sangat tergantung faktor habitat dan makanan, biasanya hidup menyendiri dilubanglubang karang mati untuk menghindari diri dari predator (Juliawan, I., D dan Nurfadillah, 2017). Secara umum Pola sebaran Diadema adalah mengelompok dan tergantung pada substrat dasar perairan. Hasil penelitian Echinometra mathaei hidup di bebatuan karang dan pasir.

Echinometra oblonga (Gambar 3.) memiliki kisaran berat tubuh yaitu 3,66-47,71 gram, dengan diameter 50-61 mm. Panjang duri primer berkisar 8-27 mm, memiliki warna duri hitam agak kecoklatan, cangkang didominasi warna hitam berbentuk oval, duri tidak terlalu panjang, tumpul, namun berjenis duri tebal. Bentuk Tuberkel perforate. Spesies ini tersebar merata di semua. stasiun pengamatan, serta ditemukan pada celah karang mati dan daerah pertumbuhan makroalga.

Echinothrix calamaris (Gambar 4.) memiliki bentuk tubuh bundar pentagonal, pipih dan berwarna hitam. Memiliki 2 jenis duri, duri pada bagian interambulakral memiliki warna belang putih di balut warna hitam bermotif cincin, duri tebal, ujung tumpul dan rapuh, sedangkan duri pada daerah ambulakral sangat tajam, halus dan sangat rapuh, bentuk bentuk Tuberkel yaitu crenulate. Ukuran tubuh berkisar antara 39-43 mm dengan berat tubuh 7,48-26,41 gram, panjang duri primer berkisar $12-30 \mathrm{~mm}$, hal ini berkaitan dengan habitatnya yaitu pada rataan pasir, daerah pertumbuhan makroalga dan padang lamun yang memiliki kerapatan sedang. Menurut Tupan dan Silaban (2017), bobot tubuh bulu babi yang ditangkap di alam berkaitan dengan tipe subsrat di habitatnya. Tipe substrat yang didominasi oleh campuran pasir berlumpur dan pecahan karang serta ditumbuhi oleh lamun yang pendek dengan kerapatan lamun yang tidak padat, biasanya memperlihatkan bobot tubuh yang lebih kecil.

Heterocentrotus trigonarius (Gambar 5.) memiliki duri primer yang tumpul dan berwarna hijau tua kecoklatan dengan duri sekunder pendek memipih berwarna coklat tua, memiliki tubuh yang bulat dengan bagian bawahnya datar dengan cangkang yang tebal dan keras, bentuk Tuberkel yaitu perforate. Ukuran diameter tubuh berkisar antara 45-63 mm, dengan berat tubuh 23,33-109,18 gram, panjang duri 
Tabel 1. Klasifikasi dan Jenis Bulu babi di Lokasi Penelitian

\begin{tabular}{llll}
\hline Ordo & Famili & Genus & Spesies \\
\hline Camarodonta & Echinometridae & Echinometra & Echinometra mathaei \\
& & & Echinometra oblonga \\
& & Heterocentrotus & Heterocentrotus trigonarius \\
Diadematoida & Diadematidae & Echinothrix & Echinothrix calamaris \\
& & Diadema & Diadema setosum \\
Stomopneustoida & Stomopneustidae & Stomopneustes & Stomopneustes variolaris \\
\hline
\end{tabular}

primer 31-40 mm, Spesies ini termasuk ke dalam bulu babi yang memiliki ukuran tubuh besar, banyak ditemukan di daerah rataan karang mati dan bebatuan yang memiliki lubang berukuran relatif besar.

Diadema setosum (Gambar 6.) memiliki bentuk tubuh bundar pentagonal dan pipih, berwarna hitam, duri berukuran lebih panjang dari tubuhnya, permukaan tajam, ujung runcing dan rapuh, sedangkan duri sekunder pendek sebagai alat pergerakan. Memiliki 5 titik putih pada bagian atas dan terletak di setiap segmen, bentuk Tuberkel yaitu crenulate. Ukuran spesies ini biasanya mencapai $70 \mathrm{~mm}$, namun yang ditemukan pada saat penelitian berkisar antara 20$40 \mathrm{~mm}$, dengan berat 4,91-6,3 gram, panjang duri primer berkisar antara $18-22 \mathrm{~mm}$. Jenis ini biasanya hidup secara mengelompok, namun saat penelitian bulu babi ini ditemukan berukuran relatif kecil dan hidup menyendiri di celah-celah karang dalam jumlah yang sangat sedikit. Menurut Suryanti dan Ruswahyuni, (2014) Bulu babi (Echinoidea) yang hidup di zona rataan pasir, daerah pertumbuhan alga dan rataan karang biasanya hidup secara mengelompok dalam kelompok besar sedangkan di daerah tubir karang bulu babi (Echinoidea) ini hidup dalam kelompok kecil atau hidup menyendiri dalam lubang karang mati dan pecahan karang.

Stomopneustes variolaris (Gambar 7.) memiliki duri tegak, permukaan kasar, beralur dan ujung tumpul. Memiliki bentuk cangkang oval dan dominan berwarna hitam kecoklatan. Ciri khas spesies ini yaitu duri akan berwarna kehijauan apabila terpapar sinar matahari. Bentuk Tubercle crenulate (ada hiasan atau permukaan kasar),serta pada bagian ambulakral sangat jelas terlihat saluran kaki tabung. Diameter tubuh berkisar antara 50-62 mm, dengan berat 7,73-22,6 gram, Panjang duri primer berkisar antara 20-40 $\mathrm{mm}$, duri sekunder berkisar antara 2- $4 \mathrm{~mm}$. menyukai habitat yang terdapat lamun, makroalga, pasir dan karang mati.

Anatomi bulu babi terdiri dari sistem pencernaan yang di dalamnya terdapat lima bagian utama yaitu mulut, kerongkongan, lambung, usus dan anus, tersusun melingkari Lentera Aristoteles. Lentera Aristoteles merupakan suatu organ yang terdiri atas gigi/rahang, tulang serta otot. Gigi/ rahang ditopang oleh ossicle yang dinamakan pyramid plate yang memiliki alur sebagai landasan dari gigi untuk bergerak ke bawah (keluar) maupun ke atas (masuk) (Hasi et al., 2016)

Hasil pembelahan bulu babi didapatkan bahwa masih terdapat bulu babi yang belum ditemukan gonad di dalamanya. Perkembangan gonad bulu babi memiliki 6 tahap yaitu developing (berkembang), recovering (pulih), growing (bertumbuh), pre mature (pramatang), mature (matang), dan spawning (salin). Gonad yang berwarna coklat dan coklat kehijauan mengindikasikan bulu babi berada di tahap recovering, gonad berwarna krem dan putih kekuning mengindikasikan gonad jantan berada pada tahap matang, sedangkan warna orange dan merah kecoklatan menunjukan gonad betina berada pada tahapan pra matang (Tupan dan Silaban, 2017). Bulu babi mempunyai kelamin yang terpisah, induk jantan mempunyai kelamin jantan (testis) yang menghasilkan sperma dan induk betina mempunyai kelamin betina (ovum) yang menghasilkan telur (Toha et al., 2012). Pembuahan terjadi diluar tubuh, pembuahan, aktivasi metabolisme perkembangan dan mekanisme pengaturan gen yang mengatur perkembangan embrio bulu babi (Vacquier, 2011)

Gonad E. mathaei (Gambar 8.) yang ditemukan berwarna orange mengindikasikan gonad betina berada pada tahap matang, serta volume gonad telah mencapai maksimum dimungkinkan telah memasuki masa memijah. Jenis E. oblonga (Gambar 9.) didapatkan gonad berwarna coklat kemerahan mengindikasikan gonad jantan berada pada tahap pramatang (premature). Sedangkan S. variolaris (Gambar 13.) gonad berwarna kuning muda mengindikasikan gonad betina berada pada tahap pramatang. Menurut Vacquier, (2011), fase matang awal (III) gonad jantan umumnya 
berwarna coklat kekuningan dan coklat kemerahan, sedangkan gonad betina berwarna kuning muda atau putih krem. Jenis E. calamaris (Gambar 10.) dan H. trigonarius (Gambar 11.), didapatkan bahwa gonad belum nampak jelas, warna gonad masih terlihat transparan, keputihputihan dan relatif tipis, menandakan gonad bulu babi bulu babi masih dalam fase berkembang (developing).

\section{Morfologi Bulu babi}

Morfologi Bulu babi Echinometra mathaei dapat dilihat pada Gambar 2.

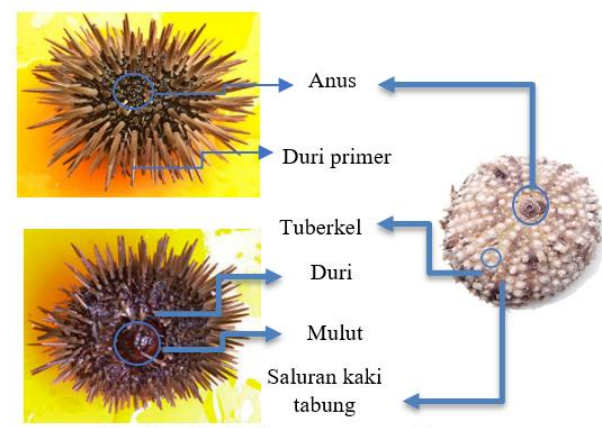

Gambar 2. Echinometra mathaei

Morfologi Bulu babi Echinometra oblonga dapat dilihat pada Gambar 3.

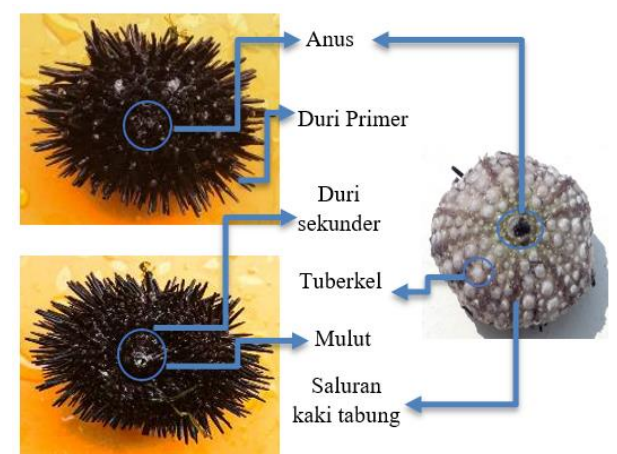

Gambar 3. Echinometra oblonga

Morfologi Bulu babi Echinothrix calamaris dapat dilihat pada Gambar 4.

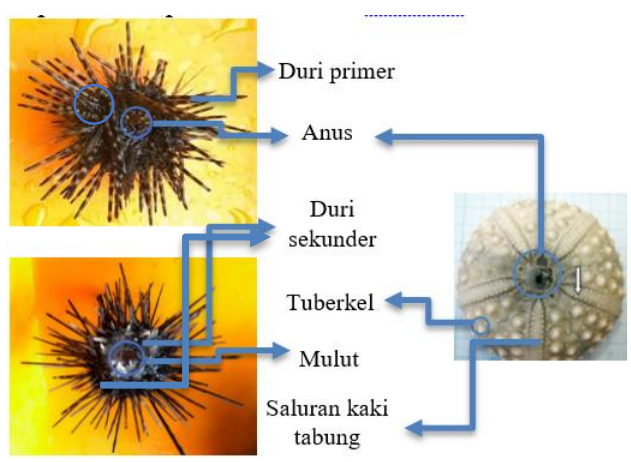

Gambar 4. Echinothrix calamaris
Morfologi Bulu babi Heterocentrotus trigonarius dapat dilihat pada Gambar 5.

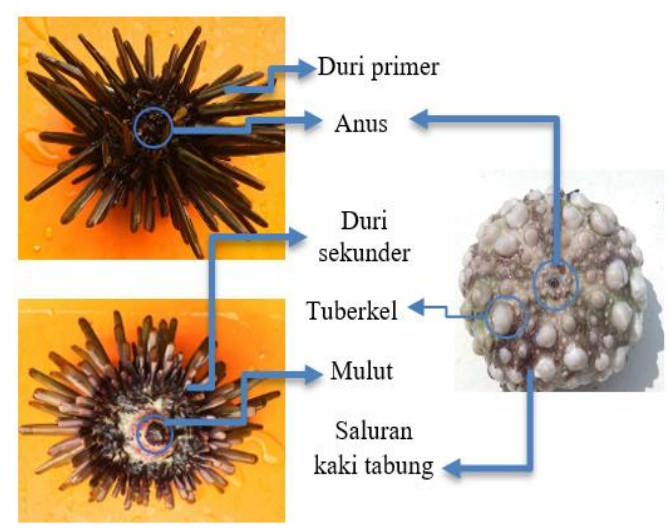

Gambar 5. Heterocentrotus trigonarius

Morfologi Bulu babi Diadema setosum dapat dilihat pada Gambar 6.

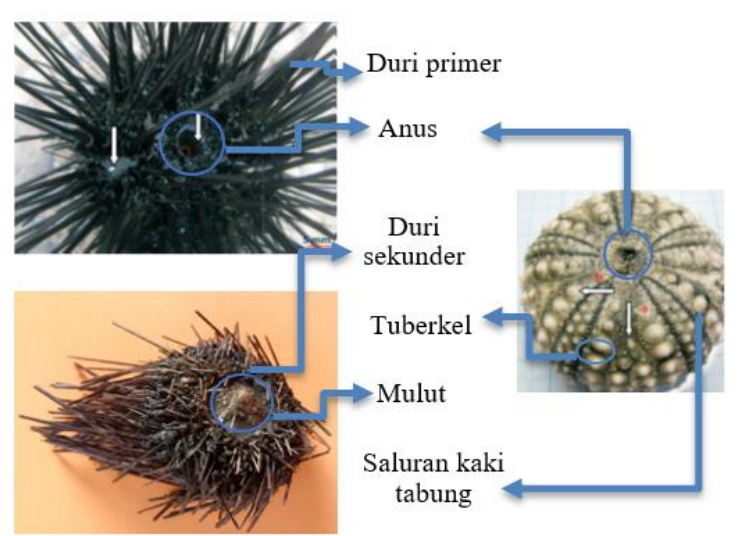

Gambar 6. Diadema setosum

Morfologi Bulu babi Stomopneustes variolaris dapat dilihat pada Gambar 7.

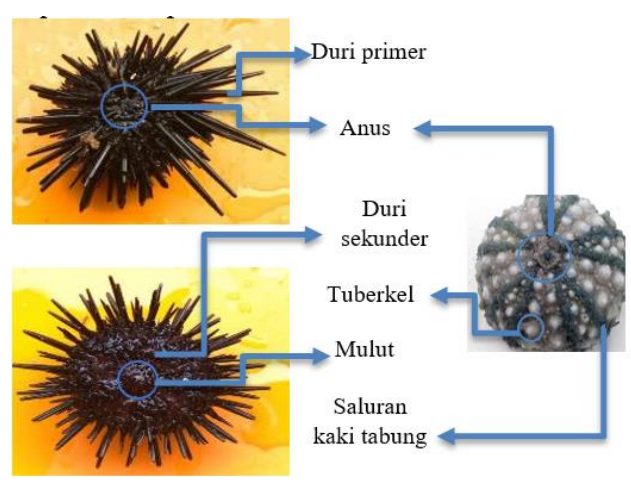

Gambar 7. Stomopneustes variolaris

\section{Anatomi Bulu babi}

Hasil pembelahan bulu babi Echinometra mathaei dilihat pada Gambar 8. 


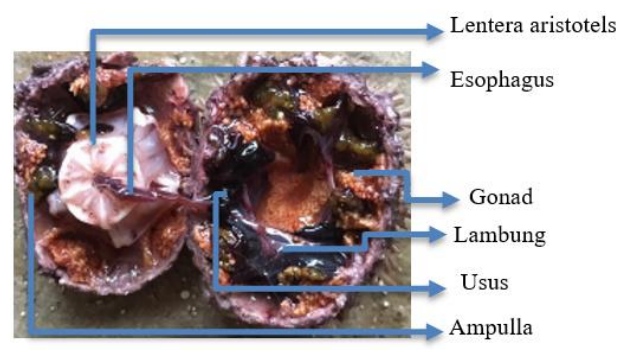

Gambar 8. Anatomi Echinometra mathaei

Hasil pembelahan bulu babi Echinometra oblonga dilihat pada Gambar 9.

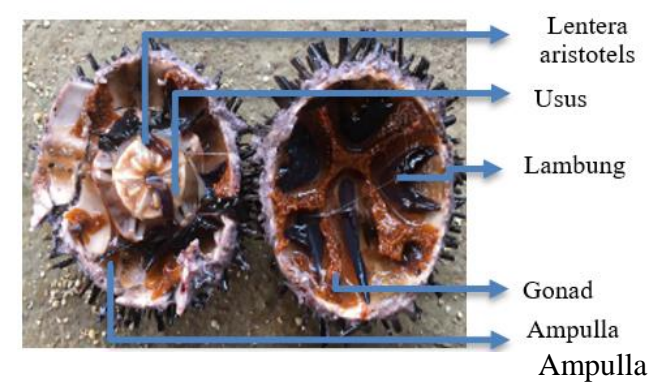

Gambar 9. Anatomi Echinometra oblonga

Hasil pembelahan bulu babi Echinothrix calamaris dilihat pada Gambar 10.

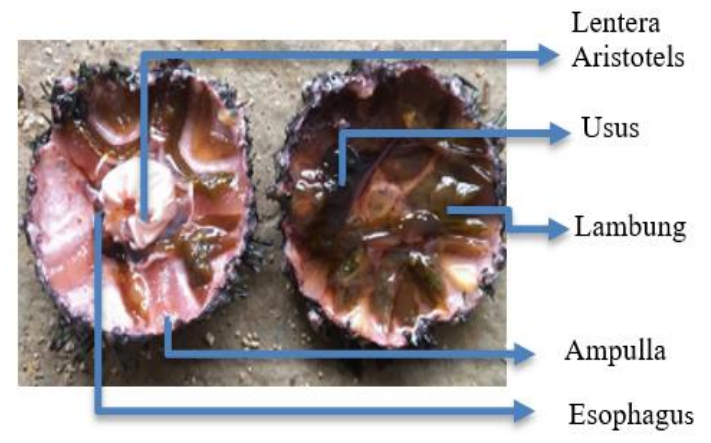

Gambar 10. Anatomi Echinothrix calamaris

Hasil pembelahan bulu babi Heterocentrotus trigonarius dilihat pada Gambar 11.

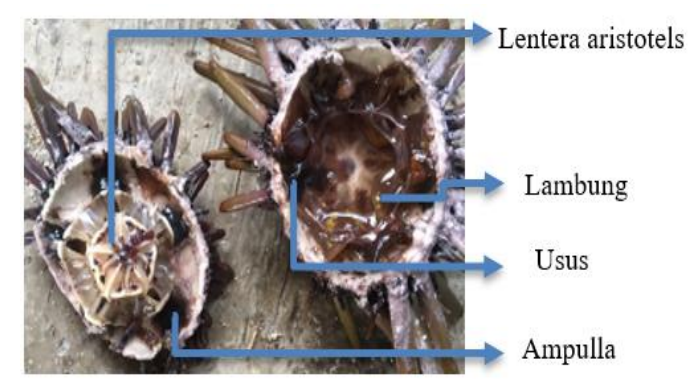

Gambar 11. Anatomi Heterocentrotus trigonarius

Hasil pembelahan bulu babi Diadema setosum dilihat pada Gambar 12.

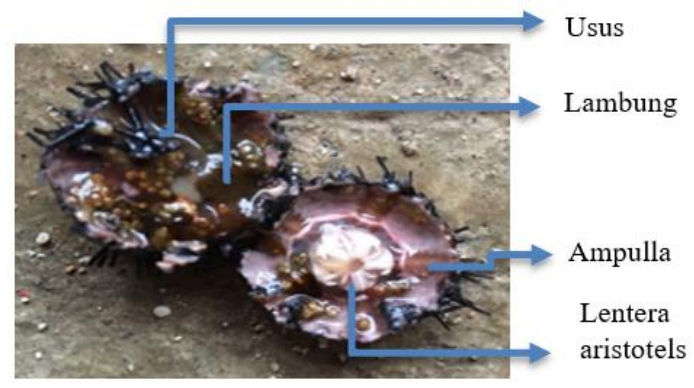

Gambar 12. Anatomi Diadema setosum

Hasil pembelahan bulu babi Stomopneustes variolaris dilihat pada Gambar 13.

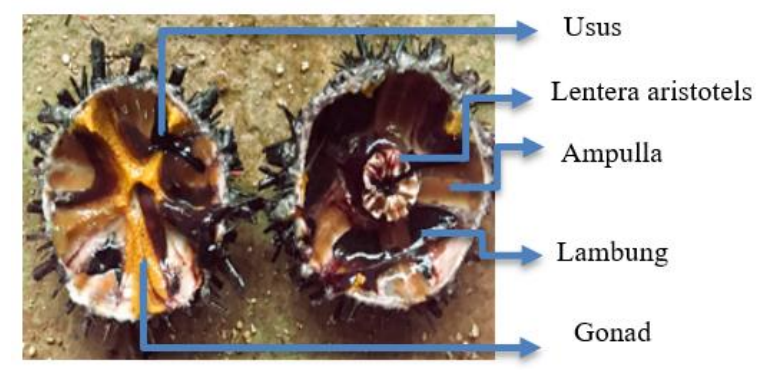

Gambar 13. Anatomi Stomopneustes variolaris

D. setosum (Gambar 12.), pada saat dilakukkan pembelahan gonad belum Nampak jelas, kemungkinan masih berada pada fase netral (0), dimana individu masih kecil/muda, gonad relatif tipis dan kenampakan semi transparan. Selain itu siklus reproduksi bulu babi di suatu perairan juga dapat dipengaruhi oleh perubahan musim dan topografinya. Menurut Tasruddin dan Aonurafiq, (2016) faktor yang menyebabkan terjadinya perbedaan indeks gonad diduga karena faktor ketersediaan makanan, musim (suhu dan photoperiode), karakteristik ekologi dan kondisi geografis.

Kelimpahan tertinggi yaitu dari jenis $E$. oblonga dengan kelimpahan relatif pada 3 stasiun berturut-turut sebesar 49,36\%, 92,14 5 dan 82,71 $\%$. Tingginya kelimpahan jenis E. oblonga diduga kerana kondisi substrat dan lingkungan yang mendukung untuk kehidupan jenis ini, selain itu jenis ini mampu beradaptasi terhadap perubahan lingkungan dan kesesuaian habitat. Pada saat penelitian jenis ini banyak ditemukan bersembunyi pada celah dan lubang karang mati yang ukurannya relatif sempit, sehingga akan mempengaruhi pertumbuhan panjang dan lebar cangkang dari bulu babi tersebut (Moningkey, 2010). Bulu babi Jenis Echinothrix. calamaris, D. setosum dan $S$. variolaris hanya ditemukan pada stasiun A yang memiliki tutupan substrat dasar 
perairan berupa lamun, karang mati, pasir dan beberapa jenis makroalga, dimungkinkan karena kondisi lingkungan dan ketersediaan makanan yang sesuai untuk kehidupan bulu babi jenis ini, sedangkan $H$. trigonarius hanya ditemukan pada stasiun B yang memiliki lubang-lubang karang relatif besar sesuai untuk tempat hidupnya, dikarenakan jenis ini menyukai habitat berupa lubang dan celah karang yang berukuran relatif besar.

Kelimpahan terendah yang ditemukan yaitu dari jenis dari jenis E. mathaei pada tiga stasiun berturut-turut sebesar 2,31\%, 1,11\% dan 17,28\%. Rendahnya kelimpahan jenis ini diduga karena Echinometra mathaei hanya menyukai lubang atau celah karang yang berukuran relatif besar di daerah rataan terumbu. Menurut Supono dan Arbi, (2012) bahwa bulu babi Echinometra mathaei memiliki tingkat kepadatan yang rendah, karena jenis ini biasanya hidup pada lubang bongkahan karang atau batu. Adaptasi bulu babi jenis Echinometra mathaei variasi coklat yaitu dengan selalu berada pada lubang tempat hidupnya untuk mempertahankan diri dari gangguan predator, pendatang dan hempasan ombak \{Formatting Citation .

Nilai indeks keanekaragaman, keseragaman dan dominansi bulu babi di Pantai Sepanjang (Tabel 3.) menunjukkan bahwa keanekaragaman rendah, keseragaman sedang dan terdapat spesies yang mendominasi.

Rendahnya keanekaragaman di suatu ekosistem dapat dipengaruhi karena komunitas disusun oleh sangat sedikit spesies dan persebaran individu tidak merata. Menurut Budiman et al. (2014) tinggi rendahnya nilai indeks keanekaragaman jenis dapat disebabkan oleh beberapa faktor, yaitu jumlah jenis atau individu yang didapatkan, adanya beberapa jenis yang ditemukan dalam jumlah yang melimpah dan homogenitas substrat. Jika suatu komunitas terdapat spesies tertentu yang mendominasi, maka keseimbangan komunitas akan menjadi tidak stabil dan akan mempengaruhi keanekaragaman dan keseragaman. Menurut Ibrahim et al. (2017) indeks dominansi dapat terjadi karena adanya hasil dari proses kompetisi penggusuran individu satu terhadap individu yang lain.

Berdasarkan analisis tekstur sedimen didapatkan kisaran ukuran butir sedimen yaitu 0,51-0,80 mm, termasuk dalam kategori pasir kasar berupa pasir dan pecahan karang mati. Bulu babi pada umumnya menghuni ekosistem Terumbu karang dan padang lamun serta menyukai substrat di padang lamun yang merupakan campuran pasir dan pecahan karang mati (Olii dan Kadim, 2017).

Berdasarkan hasil analisis kandungan bahan organik substrat dasar perairan termasuk dalam kategori rendah, berkisar antara 5,896- 6,927 \%, Rendahnya kandungan bahan organik substrat dasar perairan dikarenakan Pantai Sepanjang memiliki tekstur substrat dasar berupa pasir dan patahan karang mati. Substrat dasar perairan yang berupa fraksi kasar seperti pasir dan patahan karang mati mengandung bahan organik yang cukup rendah. Menurut Riniatsih dan Kushartono, (2010) bahwa pada tekstur substrat dasar berupa pecahan karang dan pasir memiliki kandungan bahan organik yang lebih rendah dibandingkan dengan tekstur substrat dasar berupa pasir berlumpur

Kisaran Suhu perairan pada Pantai Sepanjang berkisar antara $28-31{ }^{\circ} \mathrm{C}$, suhu yang paling baik untuk kehidupan organisme di laut berkisar spesifik sekitar $28-31{ }^{\circ} \mathrm{C}$, apabila suhu diluar kisaran suhu lingkungan maka organisme laut akan membutuhkan suatu adaptasi untuk dapat bertahan hidup. Suhu ideal untuk kehidupan hewan bentik yaitu berkisar antara $25-33{ }^{\circ} \mathrm{C}$ (Toha et al., 2012).

Tabel 2. Kelimpahan Bulu babi (1.166 ind $\left./ 45 \mathrm{~m}^{2}\right)$

\begin{tabular}{|c|c|c|c|c|c|c|c|c|c|c|c|c|}
\hline \multirow{3}{*}{ Spesies } & \multicolumn{4}{|c|}{ Stasiun A } & \multicolumn{4}{|c|}{ Stasiun B } & \multicolumn{4}{|c|}{ Stasiun $\mathrm{C}$} \\
\hline & \multicolumn{3}{|c|}{ Titik } & \multirow{2}{*}{$\begin{array}{l}\text { KR } \\
(\%)\end{array}$} & \multicolumn{3}{|c|}{ Titik } & \multirow{2}{*}{$\begin{array}{l}\text { KR } \\
(\%)\end{array}$} & \multicolumn{3}{|c|}{ Titik } & \multirow{2}{*}{$\begin{array}{l}\text { KR } \\
(\%)\end{array}$} \\
\hline & I & II & III & & $\mathrm{I}$ & II & III & & I & II & III & \\
\hline E. mathaei & 4 & 5 & 2 & 2,32 & 2 & 2 & 1 & 1,11 & 4 & 5 & 5 & 17,28 \\
\hline E. oblonga & 50 & 124 & 60 & 49,36 & 63 & 118 & 382 & 92,14 & 13 & 19 & 35 & 82,71 \\
\hline E. calamaris & 4 & 3 & 2 & 1,9 & - & - & - & - & - & - & - & - \\
\hline H. trigonarius & - & - & - & - & 1 & 2 & 40 & 7,03 & - & - & - & - \\
\hline D. setosum & 3 & 5 & 3 & 2,32 & - & - & - & - & - & - & - & - \\
\hline S. variolaris & 38 & 122 & 49 & 44,09 & - & - & - & - & - & - & - & - \\
\hline$\sum$ & & & 474 & & & & 611 & & & & 81 & \\
\hline
\end{tabular}


Tabel 3. Hasil Analisis Indeks Ekologi

\begin{tabular}{cccccccc}
\hline Stasiun & Titik & H'$^{\prime}$ & Kategori & E & Kategori & D & Kategori \\
\hline \multirow{2}{*}{ A } & 1 & 1,07 & Sedang & 0,66 & Tinggi & 0,40 & TAD \\
& 2 & 0,91 & Rendah & 0,56 & Sedang & 0,45 & TAD \\
& 3 & 0,94 & Rendah & 0,58 & Sedang & 0,44 & TAD \\
\hline \multirow{2}{*}{ B } & 1 & 0,21 & Rendah & 0,19 & Rendah & 0,91 & AD \\
& 2 & 0,16 & Rendah & 0,15 & Rendah & 0,93 & AD \\
& 3 & 0,32 & Rendah & 0,29 & Rendah & 0,82 & AD \\
\hline \multirow{2}{*}{ C } & 1 & 0,54 & Rendah & 0,78 & Tinggi & 0,64 & AD \\
& 2 & 0,51 & Rendah & 0,73 & Tinggi & 0,67 & AD \\
& 3 & 0,37 & Rendah & 0,54 & Sedang & 0,78 & AD \\
\hline
\end{tabular}

Keterangan : AD : Ada dominansi, TAD : Tidak ada dominansi

Tabel 4. Parameter Kualitas Perairan

\begin{tabular}{lccc}
\hline \multirow{2}{*}{ Parameter } & \multicolumn{3}{c}{ Stasiun } \\
\cline { 2 - 4 } & $\mathrm{A}$ & $\mathrm{B}$ & $\mathrm{C}$ \\
\hline Tekstur sedimen & $0,51-0,83$ & $0,71-0,81$ & $0,72-0,80$ \\
Bahan organik & $5,89-6,93$ & $5,89-6,92$ & $5,89-6,92$ \\
Suhu $\left({ }^{\circ} \mathrm{C}\right)$ & 28 & $28-31$ & $29-30$ \\
pH & 6,44 & $6,53-6,8$ & $6,32-6,87$ \\
Salinitas (\%o) & $30-33$ & $35-39$ & $39-40$ \\
Kecerahan & $\infty$ & $\infty$ & $\infty$ \\
Kedalaman $(\mathrm{cm})$ & $8,5-18,5$ & $4-11$ & $3-24$ \\
\hline
\end{tabular}

Nilai $\mathrm{pH}$ pada lokasi penelitian berkisar antara 6,32-6,87 hal ini menunjukkan bahwa perairan tersebut termasuk ke dalam kondisi asam namun normal untuk kehidupan organisme air. Menurut Kapsenberg et al. (2017), pH yang baik bagi bulu babi berkisar antara 7,6-8,03. Kondisi perairan yang sangat basa akan membahayakan organisme karena akan mengganggu proses metabolisme dan respirasi, disamping itu nilai $\mathrm{pH}$ yang terlalu asam akan menyebabkan mobilitas berbagai senyawa logam berat terutama ion aluminium, sehingga akan mempengaruhi kelimpahan bulu babi pada perairan tersebut.

Salinitas yang didapatkan berkisar antara 30-40\%, hal ini menunjukan bahwa kisaran salinitas pada Pantai Sepanjang tergolong tinggi. Bulu babi merupakan biota yang tidak tahan terhadap salinitas rendah, apabila kisaran salinitas disuatu perairan berkisar antara 23-26 \%o, akan mengakibatkan perubahan pigmen warna, duriduri akan rontok dan bulu babi akan menjadi tidak aktif, tidak mau makan dan akhirnya mengalami kematian (Mak \& Chan, 2018).

Pengukuran kedalaman sangat berpengaruh terhadap kelimpahan bulu babi, pada lokasi penelitian didapatkan kedalaman berkisar antara 3-24 cm, dan kecerahan bernilai tak terhingga dikarenakan pengukuran dilakukan pada saat surut terendah, dimana dasar perairan akan tampak jelas dan bulu babi terlihat bersembunyi pada celah-celah karang mati. Romimohtarto dan Juwana (2009) menyatakan bahwa cahaya mempunyai pengaruh besar namun tidak langsung, yakni sebagai sumber energi untuk proses fotosintesis tumbuhan yang menjadi makanan bulu babi. Hewan ini biasanya hidup pada daerah pantai atau dasar laut pada kedalaman 100-5000 m atau di bawah batas garis surut terendah, distribusinya luas terutama banyak ditemukan pada daerah intertidal, sering ditemukan pada lubang-lubang karang di daerah pantai atau di bawah rumput laut, dan beberapa jenis ada yang hidup dengan cara membenamkan diri di bawah substrat atau karang lunak.

Berdasarkan analisis komponen utama (PCA) didapatkan bahwa nilai korelasi antara tekstur sedimen dengan kelimpahan bulu babi yaitu $-0,047$, menunjukkan bahwa antara tekstur sedimen dengan kelimpahan bulu babi berkorelasi linier negatif cukup kuat. Bulu babi menyukai substrat yang agak keras terutama substrat di padang lamun yang terdiri dari campuran pasir dan pecahan karang, hidup bersembunyi pada bebatuan dan terumbu karang, dan hanya sebagian kecil yang menghuni substrat pasir dan lumpur, karena pada kondisi demikian kaki tabung sulit untuk mendapatkan tempat melekat. Menurut Sadam et al. (2019), Bulu babi menyukai sebaran 
habitat yang spesifik dan menyukai substrat yang agak keras, sehingga substrat memiliki pengaruh terhadap keberadaan bulu babi disuatu ekosistem.

Tabel 5. Korelasi Parameter Lingkungan dengan Kelimpahan Bulu Babi

\begin{tabular}{lc}
\hline Parameter Lingkungan & Nilai Korelasi \\
\hline Tekstur Sedimen & $-0,047$ \\
Bahan organik & 0,615 \\
Suhu & $-0,593$ \\
pH & $-0,172$ \\
Salinitas & $-0,539$ \\
\hline
\end{tabular}

Nilai korelasi Bahan organik dengan kelimpahan bulu babi yaitu sebesar 0,615, menunjukkan antara Bahan organik dengan kelimpahan bulu babi memiliki korelasi linier positif. Bahan organik dalam suatu perairan biasanya akan berdampak pada kelimpahan organisme, terdapat organisme yang tahan dan tidak tahan terhadap tingginya kandungan bahan organik, sehingga dominansi spesies dapat terjadi. Bulu babi merupakan pemakan detritus, sehingga peranannya dalam merombak sisa-sisa makanan yang tidak termakan oleh spesies lain namun dapat dimanfaatkan bulu babi, tingginya bahan organik suatu perairan akan mempengaruhi kelimpahan bulu babi, sedangkan pada lokasi penelitian bahan organik tergolong rendah tidak berpengaruh terhadap kelimpahan bulu babi. Menurut Yunita et al. (2020), kandungan bahan organik yang tinggi dalam substrat tidak selamanya menguntungkan bagi kehidupan bulu babi walaupun bahan organik merupakan bahan makannya, karena jika terlalu banyak akan menyumbat alat pernafasan.

Nilai korelasi yang didapatkan antara suhu perairan dengan kelimpahan bulu babi yaitu 0,593, menunjukkan bahwa antar suhu perairan dengan kelimpahan bulu babi berkorelasi negatif. Suhu sangat berpengaruh terhadap aktivitas metabolisme organisme akuatik dan berpengaruh terhadap pertumbuhan dan kehidupan biota. Suhu merupakan parameter yang sangat memepengaruhi pola kehidupan organisme perairan, seperti distribusi, komposisi, kelimpahan dan mortalitas. Suhu termasuk dalam faktor pembatas (limiting factor) dapat mengendalikan fisiologi, fenologi, durasi larva planktonik dan biogeografi invertebrata laut, selain itu sangat berpengaruh terhadap perkembangan singkat periode planktonik bulu babi yang mengakibatkan penurunan tekanan predasi dan mengubah hubungan antar populasi, selain itu dapat menyebabkan kenaikan metabolisme organisme perairan sehingga kebutuhan oksigen terlarut meningkat (Nasrullah et al., 2018).

Nilai korelasi antara $\mathrm{pH}$ dengan kelimpahan bulu babi sebesar $-0,172$, menunjukkan bahwa antara $\mathrm{pH}$ dengan Kelimpahan memiliki korelasi negatif sangat lemah. $\mathrm{pH}$ merupakan directive factor bagi organisme yang hidup disuatu perairan. $\mathrm{pH}$ perairan yang tinggi atau rendah akan mempengaruhi ketahanan hidup organisme yang hidup didalamnya. Nilai $\mathrm{pH}$ yang didapatkan pada Pantai Sepanjang lebih rendah dari kisaran nilai yang dapat ditoleransi oleh bulu babi yaitu berkisar antara 7,0-8,5. pH suatu perairan merupakan indikasi terganggunya perairan tersebut. Berkurangnya nilai $\mathrm{pH}$ disuatu perairan ditandai dengan semakin meningkatnya senyawa organik diperairan tersebut (Megawati et al., 2014)

Nilai korelasi antara Salinitas dan Kelimpahan bulu babi sebesar -0,539, menunjukkan bahwa antara Salinitas dan Kelimpahan bulu babi berkorelasi negatif. Apabila oksigen terlarut diperairan sedikit maka akan mempengaruhi keberadaan biota, menyebabkan stress hingga kematian. Salinitas berpengaruh terhadap kelimpahan dimana tingginya salinitas akan menyebabkan berkurangnya kelimpahan bulu babi. Perairan yang memiliki salinitas lebih rendah atau lebih tinggi, merupakan faktor penghambat (limiting factor) untuk penyebaran biota laut tertentu. Secara umum fauna Echinodermata merupakan biota laut dengan batas toleransi terhadap perubahan salinitas adalah relatif sempit. Hewan ini termasuk kedalam Osmoconformers yang bersifat stenohaline, dikarenakan bulu babi tidak tahan terhadap perubahan salinitas rendah.

\section{KESIMPULAN}

Berdasarkan hasil penelitian ditemukan 6 Jenis bulu babi yaitu Echinometra mathaei, Echinometra oblonga, Echinothrix calamaris, Heterocentrotus trigonarius, Diadema setosum dan Stomopneustes variolaris. Morfologi bulu babi terdiri dari Anus, duri primer, duri sekunder, mulut, Tuberkel dan saluran kaki tabung, sedangkan anatomi bulu babi terdiri dari esophagus, Lentera aristotels, lambung, usus, gonad dan ampulla. Uji korelasi menunjukkan bahwa terdapat korelasi positif antara Bahan organik sedimen dengan kelimpahan bulu babi, serta korelasi negatif antara tekstur sedimen, suhu, dan salinitas dengan kelimpahan bulu babi, 
sedangkan $\mathrm{pH}$ dengan kelimpahan bulu babi berkorelasi negatif.

\section{DAFTAR PUSTAKA}

Budiman, C.C., Maabuat, P.V., Langoy, M.L.D. \& Katili, D.Y. 2014. Keanekaragaman Echinodermata di Pantai Basaan Satu Kecamatan Ratatotok Sulawesi Utara. Jurnal Mipa, 3(2):97-101

Hasi, M.S., Lumingas, L.J.L. \& Lohoo, A.V. 2016. Allometry Analysis and Physiological Index of Sea Urchin Heliocidaris crassispina (A. Agassiz, 1864) (Camarodonta, Echinometridae) on the Reef Flat in Tongkeina and Malalayang Dua, Manado, Sulawesi. Jurnal Ilmiah Platax. DOI : $10.35800 /$ jip.4.2. 2016.13774

Ibrahim, I., Devira, C.N. \& Purnawan, S. 2017. Struktur Komunitas Echinoidea (bulu babi) di Perairan Pesisir Pantai Teluk Nibung Kecamatan Pulau Banyak Kabupaten Aceh Singkil. Prosiding Seminar Nasional Biotik, 193-198.

Juliawan, I.D. \& Nurfadillah. 2017. Kelimpahan dan Pola Sebaran Bulu Babi (Echinoidea) di Perairan Pulau Klah Kota Sabang. Jurnal Ilmiah Mahasiswa Kelautan dan perikanan Unsyiah. 2(4):541-546.

Kapsenberg, L., Okamoto, D. K., Dutton, J. M., \& Hofmann, G. E. (2017). Sensitivity of Sea Urchin Fertilization To Ph Varies Across A Natural pH Mosaic. Ecology and Evolution. https://doi.org/10.1002/ece3.2776

Mak, K. K. Y., \& Chan, K. Y. K. 2018. Interactive Effects of Temperature and Salinity on Early Life Stages of The Sea Urchin Heliocidaris crassispina. Marine Biology. https://doi.org/10.1007/s00227-0183312-4

Megawati. C., Yusuf, M. \& Maslukah, L. 2014. Sebaran Kualitas Perairan Ditinjau dari Zat Hara, Oksigen terlarut dan $\mathrm{pH}$ di Perairan Selat Bali Bagian Selatan. Jurnal Oseanografi. 3(2):142-150.

Moningkey, R.D. 2010. Pertumbuhan Populasi Bulu Babi (Echinometra mathaei) di Perairan Pesisir Kima Bajo Kabupaten Minahasa Utara. Jurnal Perikanan dan Kelautan, Unsrat, Manado. 6(2):73-78.

Nasrullah, R., Sari, W. \& Mellisa, S. 2018. Tingkat Kematangan Gonad Bulu Babi (Tripneustes gratilla) di Pantai Ahmad Rhang Mayang Kecamatan Mesjid Raya Kabupaten Aceh Besar. Jurnal Ilmliah Mahasiswa Kelautan dan Perikanan
Unsyiah. 3(10):23-32.

Odum, E.P. 1993. Dasar-Dasar Ekologi. Terjemahan Tjahjono Samingan. Edisi Ketiga. Yogyakarta. Gajahmada University Press. Hal 134-162.

Olii, H. \& Kadim, M.K. 2017. Kepadatan dan Pola Sebaran Bulu Babi di Desa Lamu. Nike : Jurnal Ilmiah Perikanan dan Kelautan. 5(2): 48-53.

Prasetyo, K., Zaida, A., Wulandari, R., Wulan, I.N., Santiati, E. \& Prakoso, C.N.Y. 2019. Kekayaan Jenis Bulu Babi (Sea Urchin) di Kawasan Perairan Pantai Gunung Kidul, Yogyakarta Species, Journal of Chemical Information and Modeling, 12(1).33-39.

Radjab, A.W. 2001. Reproduksi dan Siklus Hidup Bulu babi. Oseana 26(3):25-36.

Riniatsih, I. \& Kushartono, E.W. 2010. Substrat Dasar dan Parameter Oseanografi Sebagai Penentu Keberadaan Gastropoda dan Bivalvia di Pantai Sluke Kabupaten Rembang. Ilmu Kelautan, Indonesian Journal of Marine Sciences. 14(1):50-59.

Ristanto, A., Yanti, A.H. \& Setyawan, T.R. 2017. Komposisi Jenis Bulu Babi (Kelas : Echinoidea) di daerah Intertidal Pulau Lemukutan Kabupaten Bengkayang. Jurnal Protobiont. 6(1):59-63.

Romimohtarto, K \& Juwana, S. 2009. Biologi Laut: Ilmu Pengetahuan Tentang Biota Laut (Cetakan Ke 4). Djambatan: Jakarta. Hal 540

Sadam, L.O., Elmiyarti \& Ira. 2019. Keanekaragaman Bulu Babi (Echinoidea) pada Kawasan Lamun di Perairan Desa Langara, Kecamatan Wawoni Barat Kabupaten Konawe Kepulauan. Jurnal Sapa Laut. 4(3):113-122.

Supono \& Arbi, U.Y. 2012. Kelimpahan dan Keragaman Echinodermata di Pulau Pari, Kepulauan Seribu. Jurnal Ilmu Dan Teknologi Kelautan Tropis. 4(1):114-120.

Suryanti \& Ruswahyuni. 2014. Perbedaan Kelimpahan Bulu Babi (Echinoidea) pada Ekosistem Karang dan Lamun di Pancuran Belakang, Karimunjawa Jepara. Jurnal Saintek Perikanan. 10(1), 62-67.

Suryanti, S., Ain, C., Latifah, N., \& Febrianto, S. 2017. Mapping of Sea Urchin Abundance as Control of Algae Expansion for the Balance of Coral Reef Ecosystem in Karimunjawa Islands. Journal of Applied Environmental and Biological Sciences. 7(12):120-127.

Tasruddin \& Aonurafq. 2016. Perbandingan Aspek Ekologi dan Karakteristik Bulu Babi Tripneustes gratilla pada Lokasi berbeda. 
Jurnal Akuakultur Indonesia. 15(2):139-146.

Toha, A.H.A., Pramana, A., Sumitro, S.B., Hakim, L., \& Widodo, W. 2012. Penentuan Jenis Kelamin Bulu Babi Tripneustes gratilla Secara Morfologi. Journal of Biological Researches. 17:211-215.

Tupan, J. \& Silaban, B. 2017. Karakteristik Fisik Kimia Bulu Babi Diadema setosum dari Beberapa Perairan Pulau Ambon. Jurnal Manajemen Sumberdaya Perairan. 13(2):7178.
Vacquier, V.D. 2011. Laboratory on sea urchin fertilization. 78(8):553-564. Molecular Reproduction and Development. DOI : $10.1002 / \mathrm{mrd} .21360$

World Register of Marine Species (WoRMS). 2020. http://www.marinespecies.org (di akses 19 Maret 2020)

Yunita, R.R., Suryanti, S. \& Latifah, N. 2020. Biodiversitas Echinodermata pada Ekosistem Lamun di Perairan Pulau Karimunjawa, Jepara. Jurnal Kelautan Tropis. 23(1):47-56. 